\title{
BIASES AND INFLUENCING FACTORS IN RISK PERCEPTION
}

\author{
Virginia ANDREI ${ }^{1}$
}

DOI: $10.35782 / J C P P .2019 .1 .02$

\begin{abstract}
The aims of this paper are to analyze the causes and implications of risk perceptions and to review the theories developed nowadays. One of the main concepts outlined in risk psychology literature is cognitive biases, which refers to cognitive shortcuts used subconsciously by every individual in order to understand a bazardous situation and act upon it. The qualitative research for this study has identified various ways to process risks and various associations made by respondents when talking about the risks perceived in their lives. Some of the answers bave been gathered in this paper, which tries to identify connections with well-known biases in riske. psychology. Research findings will help in the elaboration of the author's $\mathrm{PhD}$ thesis.
\end{abstract}

Keywords: risk; risk perceptions; cognitive biases; emotions; media.

\section{Introduction}

Studying risks is not only about scientific risk analyses, methods to describe and analyze risks, percentages and mathematical formula. It is also about a subjective perspective, within which risk numbers become feelings or cognitive biases. From a psychological point of view, risks are replaced by fears, are compared to previous experiences and are analyzed using cognitive shortcuts.

Studies of risk perceptions - such as the ones developed by Paul Slovic, Ellen Petters, Alhakami A.S. or Chauncey Starr - do not simply correlate risks with individual and subjective items used by individuals to evaluate risk and but also investigate attitudes and behaviors developed in risk situations and analyze people's reasoning regarding unknown and feared risks. There is also a focus on ,the influencers' involved in risk processing, from the individual level to the societal one (social amplification of risks, specific cultural context, media pressure) (Douglas \& Wildavsky, 1982).

The aim of this paper is to outline the main theories and studies carried out over risk psychology, in order for them to be further used in the author's $\mathrm{PhD}$ thesis Focus

$1 \mathrm{PhD}$ Candidate at the Faculty of Sociology, University of Bucharest. Research interests: risk assessment, risk perception and risk communication. E-mail address: virginia.andrei22@ yahoo.com. 
group discussions on risk communication were conducted during January and March 2019, as part of the doctoral research.

The author conducted four focus-groups discussion: two in Bucharest and other two in Cluj-Napoca. Every focus-group discussion was held with minimum six participants (six, respectively seven for the discussions in Bucharest and seven, respectively eight for the ones in Cluj-Napoca). Therefore, 28 people were involved in the study. Every discussion was based on 45 questions regarding spontaneous associations to risk, individual or national risks, feelings generated by the risks mentioned, the level of trust in Romanian media, opinions and data known about the risks. There was also a debate on the probability and impact of the democracy decay risk in Romania or the chances for an economic crisis to happen in the next months. The final topics covered referred to risk messages (the participants were asked to assess a risk, starting from a risk message drawn up by the researcher) and to risk scenario (the participants were asked to imagine they are part of a crisis management team and have to communicate to the public on the possibility for an earthquake to happen in the following days).

The discussions lasted about 90-120 minutes and took place at the headquarter of a research institute. The participants were called few days before the agreed fixture for the activity. The researcher did not provide details over the discussions' topic.

Some of the main items investigated were the ways people understood and described risk, as well as the correlations made by respondents with the risks mentioned. Moreover, the author was interested in the respondents' choice for risks (why do they think some risks are more important than others and why the risks mentioned matter for them).

Thus, the article will outline the main theories and studies regarding risk perceptions and will debate over the meaning and applications of concepts like risk, risk perceptions, risk attitude, cognitive strategies and biases used in order to cope with risk situations, by using examples from the author's doctoral research.

\section{Literature Review}

Main contributions to risk perception are brought by Paul Slovic's research into intuitive reactions to danger and individual reasoning within risky situation. In a study developed together with Ellen Peters, the authors focus on affect, defined as an emotional stimulus that guide individual reactions to risk: attitudes, behavior, decisions taken in order to face complex, risky or uncertain situations (Slovic \& Peters, 2006, p. $322)$.

Risk as a feeling refers to emotions used intuitively by people in order to estimate risks. For example, anger attenuates risk assessments, while fear amplifies it or makes the individual perceive some risks as being more important than others, even if there is no evidence for such a conclusion. For example, terrorist attacks are commonly feared risks, therefore perceived as important, major, probable to happen even if, according to experts, there are other risks that cause annually more damages than terrorist attacks, such as car accidents (Fischhoff et al., 1978, p. 129). 
Other studies conducted by Slovic highlight the correlation between the benefit perceived by individuals and the feelings generated by the risks assessed or managed. In other words, people asses a risk not only by what they think or know about it, but also by how they feel about it or how they felt at a certain point in the past. If their feelings are positive, then the benefits perceived are high. The opposite is true: if the feelings are negative, the benefits perceived are low and the negative consequences are high (Alhakami \& Slovic, 1994, p. 323).

Starting from the influence of feelings on individual risk perceptions and attitudes, providing data about beneficial or negative consequences of some risks could change people's perception and reaction to the hazards in question (Slovic \& Peters, 2006, p. 324). For example, delivering data through media regarding the positive development on Romania's economy could increase the benefits perceived by people and decrease the negative implications, therefore totally changes people's perceptions on this subject.

Another item taken into consideration regarding perceptions and attitudes towards risks is developed by Chauncey Starr and refers to the voluntary and imposed character of the hazardous situation. In other words, a risk becomes acceptable when it is selfimposed and unacceptable when it is generated by others (Starr, 1969, p. 1235). For example, the risks generated by skiing are not perceives as important or major because it's a leisure activity chosen and assumed by individuals whereas the risks implied by political instability or interstate conflict are totally unacceptable, being generated by external and uncontrolled factors.

A common mistake people make when taking decisions towards risky situations is neglecting risk probability. When there are negative consequences that can have an affective meaning, the chances for the hazard to happen are not taken into consideration. Being insensitive to risk probability could cause exaggerated reactions and decisions to facts that are unlikely to happen (Slovic \& Peters, 2006, p. 324).

An integrated approach to risk perception is developed by Slovic and is called the psychometric paradigm. It covers a large number of risks assessed according to the familiarity of the risks and the fears individuals have towards the risks. The psychometric paradigm was drawn up starting from people's opinions and knowledge on risks' magnitude, negative dimension, data gathered through opinion surveys. The paradigm reveals a prioritization of risks, made by individuals, based on their fears and lack of knowledge on risk chances to happen and possible impact on their lives (Slovic, 1987, p. 280-282).

Apart from feelings, socio-cultural dimensions could influence risk perception as well. The social amplification of risk, for example, refers to the route taken by risks in order to have a major negative impact on society and to become feared or highly debated (Kasperson \& Kasperson, 2005). Another dimension debates the role played by culture, as a background that generates a positive or negative risk assessment, before the individual understands the hazardous situation (Douglas \& Wildavsky, 1982). 


\section{Psychology of risk: key definitions}

By describing an event or a situation as risky, we refer to possible negative consequences that could affect valuable items for us: our assets, job, or even our friends, family, or our life. Therefore, describing and analyzing risks involves two main dimensions: probability and impact. The first one refers to the chances for the risk event to happen and the second one to the negative outcome of the risk manifestation (Zinn, 2008, p. 14).

This definition doesn't focus on the subjective dimension of risk analysis, which is best represented by individual risk perceptions. Understanding risk perception and its role in analyzing risks is important not only within the scientific approach (which consists in analyzing risks by experts, following certain procedures and methods), but also in the individual one (people assess risk information in their own way, not knowing details about risk analysis processes and methods) (Zinn, 2008, p. 5-6).

Risk perception refers to risk processing, more specifically to individual responses to risk and cognitive strategies used to deal with risk information and to assess the magnitude of the risk, in order to decide regarding the upcoming risk. Without the capacity to scientifically analyze the risks we face, we only use our risk perceptions, together with our intuition.

By cognitive strategies we understand the rational (mental) approach to risk information: trying to make sense of new, uncertain data and to use some of the beliefs and last experiences with similar situations, in order to cope with the new one and make the best decision (Slovic, 2000, p. 10-13).

In most cases, due to lack of time, attention and know-how, we are not capable of processing the risk: to make connections between the pieces of relevant information and to draw proper conclusions. Thus, we use shortcuts to assess risks and to take decisions regarding possible negative consequences, even if we shouldn't always rely on this subjective mechanism (Assailly, 2010, p. 68-72).

The two approaches (rational and subjective) used to process risk information are also called experiential and analytic. The first one is based upon feelings, associations, intuition, unconscious, impulsiveness, whereas the second one consists of data analysis, logic, consciousness, measurements, estimations, memory and attention (Assailly, 2010, p. 10).

In trying to analyze a risky situation, people use their main beliefs and the knowledge that they possess in order to understand the new risk data. They connect the risk event with similar situations from the past, try to identify its causes and consequences, ways to control risk, responsible actors and, finally, they manage to take an informed decision towards the risk (Fischhoff, 1985, p. 21-22).

Using mental shortcuts, people do not manage to cover the real dimension of the risk assessed. Moreover, they become influenced by certain items, used in order to build up an individual defense or prevention mechanism. The most common cognitive biases involved in risk processing are the following: 
- spontaneous associations;

- the negative impact of the risk;

- proximity to the risk assessed;

- perception over individual capacity to face the risky situation;

- the emotions revealed by the risk, mostly the negative ones such as fear;

- the risk's extension;

- the trust we have in the ones responsible to manage the risk;

- media coverage over the risk;

- knowledge about the risk or about similar situations (Fischhoff, 1985, p. 24).

\section{Cognitive biases in practice}

\section{Spontaneous associations with risk: analyzing biases}

The word "danger" was the most mentioned association with risk, together with negative outcomes, damages at a national or individual level and earthquake. The second most mentioned word was "probability" - the fact that the danger is not imminent, it is likely to happen. The less frequently mentioned correlations were opportunity, win, positive outcome, ,no risk, no gain'/ These latter responses indicate that some people, though not many, not only perceived the negative dimension of risk, but also the positive ones.

In order to analyze the answers of respondents, the findings about risk associations have been categorized into informed and emotional ones. Analyzing the spontaneous associations outlined above, we can say that the emotional approach was more present during focus group discussions, given the large number of people who talked about risks in negative terms.

"Something you should not ignore" or ,something that you should avoid" were some of the definitions provided by the respondents. In other words, it means that we should take a decision in order to manage a risky situation. These definitions also reveal risk attitudes towards risk: avoiding or managing loses.

\section{The role of media; the influence of personal and professional experience}

Asked about the most important risk for Romania in upcoming years, many opinions have led to educational issues. The risks mentioned were: lots of people are becoming easy to manipulate due to their lack of education, Romania's future is in the hands of today's children, who are not properly educated.

Possible reasons why people thought educational driven risks to be more important than others may be media content shared about this issue, personal experiences (participants offered examples from their own lives) and also the spread of the risk (one of the respondents claimed that the proportion of functional illiteracy affects $40 \%$ of the country's entire population). 
The wide extent of corruption, the incapacity of politicians to take decisions for the safety of citizens, the political instability and damages brought to democracy are frequently mentioned risks. The details offered on this subject revealed a pessimistic approach regarding Romania's political development, also fuelled by the data known on the subject. This negative perspective may have been influenced by personal opinions, past experiences and also by media coverage on topics like public manifestations, analyses over Government's decisions, over public speeches of our rulers, negative public reactions from EU countries over latest domestic developments. These topics and others were detailed by the ones asked, when talking about the risks from the political field.

People perceived risks differently, in terms of natural disasters, economic issues for them or for the entire country, educational matters. Their opinions seem to be mostly influenced by their profession and every-day activities. For example, one participant, who runs a charity for children, mentioned disease risk as being important for him.

\section{The risk extension}

Risks that could have a national impact - such as earthquakes, economic crisis and diseases - were perceived as being more important than others and highly probable by some respondents.

Asked which risks are the most important for them, some participants mentioned risks that could affect a large number of people and prioritized these risks by taking into account only the criterion of how many people might be harmed by the negative outcome.

\section{Perception over individual capacity to face the risky situation}

Some participants said that they lacked the capacity to manage risks such as economic crises or political instabilities. Respondents blamed someone else for the development of risk and believed that they could not do anything to improve the situation since the risk had already been widespread at a societal level. Participants also identified as main causes of the risks the latest decisions made by the Government of the country and the political and economic trends in Europe, mostly even in developed EU countries.

There were also people who said it was possible to individually manage the risks. For example, in order to avoid financial collapse, one respondent (with economic studies) claimed that our financial situation, our decisions can influence the economic development of our country.

The difference discovered between the optimists (strong believers in the individual capacity to face the risk) and the pessimists (respondents who did not believe in the role of individual capacity to manage the risk) is their level of knowledge: the optimists are higher educated people, with an interest towards and knowledge of risk, while pessimists have only mentioned negative outcomes of risk, without having detailed knowledge. 


\section{Emotions revealed}

The risks mentioned by some participants blended into their fears. For example, functional illiteracy was the highest concern of one respondent, not only for himself, but also for the entire country.

Their worries for their future or the country's future were the risks participants prioritized among others. The incapacity of the Government to financially sustain its citizens was one of the risks frequently mentioned by respondents. The discussions began from the actual state of the country, the latest decisions taken by the Government to raise the amount of the wages and pensions and lead to a major perceived risk for Romanians, on a long term, namely the default risk.

There were no positive emotions associated with the risks mentioned. People only referred to fear, concern, disgust, anger, shame when asked to correlate the risks mentioned with an emotion. Moreover, they seemed to mix their opinions about the actual governance with the negative risks' descriptions. The trust people have in authorities and their perceptions of safety and of important issues Romania faces nowadays were also root causes of their arguments, risk evaluations and prioritization.

\section{Knowledge about risk}

Asked how they are exposed to the risk mentioned, some of the respondents distinguished between close risks and long-term risks. This ability mostly came from the high level of knowledge owned about political, economic or social reality from Romania or outside the borders.

In some cases, even they heard and read about the risk discussed, their answers were driven by emotions, not by their expertise. This is the case for one of the respondents who firstly defined risk as a probable negative event and afterwards claimed the risk of autocracy to an important one, a direct consequence on a short term, due to the actual political instability, without having logical arguments to sustain it.

\section{Conclusions}

One of the most important conclusions of this study is that there aren't risk perceptions only driven by one bias, one rationale, one event or one context. Almost every risk evaluation represents a mix of feelings, knowledge, beliefs about the latest domestic and foreign developments, every-day experiences and professional activities.

Studying risk perceptions is difficult due to the mix of items involved in the process of processing risks. There can be perceptions driven by the context of speaking, the latest news, latest experiences or complaints, issues that could affect participants and also their families and friends on a long term.

Once identified, these perceptions can act as triggers to change misjudgments about the debated risk. Debating over risks shows not only the power of biases over how people think but also their fears and main concerns. There were some cases where the respondents delivered only negative arguments when talking about the most important 
risks for Romania's future. They were constantly trying to convince the researcher to believe just how imminent the risk was not only for them, but also for all of us.

There were few participants optimistic about their future and fewer that thought they had the power to individually manage risks. Different levels of knowledge regarding the risks debated and different areas of interests revealed obvious differences in risk perceptions and evaluations. The associations and evaluations made regarding the perceived risks were mostly driven by fears, concerns and less by knowledge and logical arguments.

Last but not least, an in-depth analysis over these research results can reveal a risk perception matrix that can be used for better communicating risks around us, important for our safety and future. Knowing which the associations and the opinions are, that people share about one risk, we can formulate risk messages, using the terms and correlations made by the majority of the target audience.

\section{References}

Alhakami, A.S. \& Slovic, P. (1994). A Psychological Study of the Inverse Relationship Between Perceived Risk and Perceived Benefit. Risk. Analysis, 14(6), 1085-1096.

Assailly, J.-P. (2010). The Psychology of Risk. New York: Nova Science Publishers.

Douglas, M, \& Wildavsky, A. (1982). Risk and Culture. Berkeley: University of California Press.

Fischhoff, B. (1985). Prejudices about Bias. Oregon: Decision Research.

Fischhoff, B., Slovic, P., Lichtenstein, S., Read, S. \& Combs, B. (1978). How safe is safe enough? A psychometric study of attitudes towards technological risks and benefits. Policy Sciences, $9(2), 127-152$.

Kasperson, J. X., \& Kasperson, R. E. (2005). The Social Contours of Risk, Publics, Risk Communicationes the Social Amplification of Risk, Volume I. London: Earthscan.

Slovic, P. (1987). Perception of Risk. Science, 236 (4799), 280-285.

Slovic, P. (2000). The Perception of Risk. New York: Earthscan.

Slovic, P. \& Peters, E. (2006). Risk Perception and Affect. Association for Psychological Science: Current Directions in Psychological Science, 15(6), 322-325.

Starr, C. (1969). Social Benefit versus Technological Risk. Science, 165, 1232-1238.

Zinn, J. O. (2008). Social Theories of risk and uncertainty. Malden: Blackwell Publishing. 